\title{
What makes health systems resilient against infectious disease outbreaks and natural hazards? Results from a scoping review
}

Jennifer B. Nuzzo ${ }^{1}$, Diane Meyer ${ }^{1 *}$ D, Michael Snyder ${ }^{1}$, Sanjana J. Ravi ${ }^{1}$, Ana Lapascu², Jon Souleles², Carolina I. Andrada ${ }^{1}$ and David Bishai ${ }^{2}$

\begin{abstract}
Background: The 2014-2016 Ebola outbreak was a wake-up call regarding the critical importance of resilient health systems. Fragile health systems can become overwhelmed during public health crises, further exacerbating the human, economic, and political toll. Important work has been done to describe the general attributes of a health system resilient to these crises, and the next step will be to identify the specific capacities that health systems need to develop and maintain to achieve resiliency.

Methods: We conducted a scoping review of the literature to identify recurring themes and capacities needed for health system resiliency to infectious disease outbreaks and natural hazards and any existing implementation frameworks that highlight these capacities. We also sought to identify the overlap of the identified themes and capacities with those highlighted in the World Health Organization's Joint External Evaluation. Sources of evidence included PubMed, Web of Science, OAlster, and the websites of relevant major public health organizations.

Results: We identified 16 themes of health system resilience, including: the need to develop plans for altered standards of care during emergencies, the need to develop plans for post-event recovery, and a commitment to quality improvement. Most of the literature described the general attributes of a resilient health system; no implementation frameworks were identified that could translate these elements into specific capacities that health system actors can employ to improve resilience to outbreaks and natural hazards in a variety of settings.

Conclusions: An implementation-oriented health system resilience framework could help translate the important components of a health system identified in this review into specific capacities that actors in the health system could work to develop to improve resilience to public health crises. However, there remains a need to further refine the concept of resilience so that health systems can simultaneously achieve sustainable transformations in healthcare practice and health service delivery as well as improve their preparedness for emergencies.
\end{abstract}

Keywords: Resilience, Health system strengthening, Health system resilience, Quality improvement, Health security, Outbreak, Natural hazard

\footnotetext{
* Correspondence: dmeyer10@jhmi.edu

${ }^{1}$ Johns Hopkins Center for Health Security, 621 East Pratt Street, Suite 210,

Baltimore, MD 21202, USA

Full list of author information is available at the end of the article
}

(c) The Author(s). 2019 Open Access This article is distributed under the terms of the Creative Commons Attribution 4.0 International License (http://creativecommons.org/licenses/by/4.0/), which permits unrestricted use, distribution, and reproduction in any medium, provided you give appropriate credit to the original author(s) and the source, provide a link to the Creative Commons license, and indicate if changes were made. The Creative Commons Public Domain Dedication waiver (http://creativecommons.org/publicdomain/zero/1.0/) applies to the data made available in this article, unless otherwise stated. 


\section{Background}

Health system resilience has been previously defined as "the capacity of health actors, institutions, and populations to prepare for and effectively respond to crises; maintain core functions when a crisis hits; and, informed by lessons learnt during the crisis, reorganize if conditions require it" $[1,2]$. For many countries, the 20142016 Ebola outbreak in West Africa was a wake-up call regarding the critical importance of having resilient health systems. In each of the three countries most affected by Ebola, a fragile health system was quickly overwhelmed by the complexity of tracking cases, the need to create and disseminate communication strategies, and the challenges of safely caring for a surge of critically ill patients. Health workers were 21-32 times more likely to have been infected with the virus than members of the general public [3]. Sickened health workers could no longer care for Ebola patients, and poor infection control in healthcare facilities contributed to nosocomial Ebola transmission. In turn, heightened risks of nosocomial Ebola infection increased public fear around hospitalization [4]. Rather than helping to contain Ebola, health systems became an amplifier of disease, exacerbating the human, economic, and political toll of the outbreak.

Similarly, unprepared health systems across the world inadvertently contributed to disease transmission during recent epidemics of Severe Acute Respiratory Syndrome (SARS) and Middle East Respiratory Syndrome (MERS) [5]. Health systems that were unprepared for disasters were also unable to provide essential services, even in highly developed countries (e.g., Canada during SARS [6], Korea with MERS [7], and the US following Hurricane Sandy [8]). Many countries have committed resources and efforts toward health system strengthening based on these recent disasters, but actionable plans and approaches to build resilient health systems have not yet achieved consensus.

Independent reviews of the global response to the 2014-2016 Ebola outbreak have stressed the importance of establishing metrics to assess and monitor progress towards improving countries' capacity to respond to public health emergencies [9-11]. In 2016, the World Health Organization (WHO) created the International Health Regulations (IHR) Joint External Evaluation (JEE) tool-a framework and process designed to measure countries' capacities to implement the requirements of the IHR, which include the ability to prevent, detect, and respond to public health emergencies of international concern [12]. Since its introduction, the JEE has become an important tool used by countries to assess their capacities for infectious disease outbreaks and other public health emergencies. To-date, more than 100 countries have conducted JEE assessments [13]. Some countries that have undergone JEE assessments have also begun to develop action plans to address gaps found in their JEEs. Despite this progress, health facilities continue to be vulnerable to public health emergencies [14].

Important work has been done to describe the general attributes of a resilient health system [1, 2, 15-17]. For example, Kruk et al. describe a resilient health system as one that is "integrated with existing efforts to strengthen health systems," able to "detect and interpret local warning signs and quickly call for support," able to provide care for a diverse population, able to "isolate threats and maintain core functions," and is able to "adapt to health shocks" [2]. However, as highlighted by Turenne et al., there continues to be a lack of clarity around the conceptualization of health systems resilience [18].

The aim of this scoping review was to draw from existing literature to characterize specific capacities required to build resilient health systems in the face of infectious disease emergencies and natural hazards, with an emphasis on highlighting potential efforts that health system actors (e.g. health facilities and health service delivery organizations that are not always well-integrated in government-led preparedness initiatives) could pursue to achieve desired health outcomes during health crises. We also sought to examine the extent to which capacities that are associated with resilient health systems are addressed by existing frameworks for measuring and motivating countries' health security, such as the JEE.

\section{Methods}

We searched the scholarly and grey-literature databases to identify which capacities should be included in a framework for assessing and improving health system resilience to infectious disease outbreaks and natural hazards. We also sought to determine whether there were existing frameworks that highlighted these capacities that could be used in low-, middle-, and high-income settings. For the purposes of our research, we used the WHO definition of health systems, defined as "all the activities whose primary purpose is to promote, restore, or maintain health" [19]. Specifically, we integrated literature in the following three areas: health security, health systems strengthening, and quality improvement. The aims of this research were to characterize the impacts that infectious disease outbreaks and natural hazards have on health systems; to identify challenges in maintaining health service delivery during outbreaks and natural hazards; and to identify strategies for effecting sustainable change in health systems-strengthening efforts.

Literature databases included PubMed, Web of Science, and OAIster. Key search terms were informed by, but not inclusive of, Kruk et al.'s definition of a resilient health system, and included "health system," "health system strengthening," "resilience," "recover," 
"quality improvement," "infectious disease," "outbreak," "natural disaster," "global health security," "pandemic," "outbreak response," and "essential functions," as well as a variety of different pathogens responsible for recent infectious disease outbreaks (e.g., SARS, Ebola) and natural hazard types (e.g., cyclone, earthquake). ${ }^{1}$ See Additional file 1: Table S1 for the full electronic search strategy. Additionally, we examined the websites of major relevant public health organizations (WHO, the Rockefeller Foundation, CDC Stacks) to identify articles and frameworks not indexed in the aforementioned databases.

All but one of the search results were filtered to include only those articles published during or after 2002, to capture literature emanating in the wake of the SARS epidemic, up until February 2018, the end of the study period. However, one search term did included articles published during or after 1990, to capture more broadly those resources that focused on essential health functions. Only English-language articles were considered. We included documents if they described health system capacities that could potentially strengthen health system resilience to either infectious disease threats or natural hazards. Documents were excluded if they described health capacities that were outside the aims of this research, as defined previously (i.e. articles that were purely about public health capacities that did not mention the relationship of these capacities to the healthcare system). For example, articles that described the importance of a trained epidemiologic workforce (a public health capacity) in outbreak identification and mitigation would be excluded. Articles about the importance of engagement between Ministries of Health and the public would be excluded; however, articles about the importance of engagement between healthcare facilities and Ministries of Health would be included. Documents were also excluded if the article described resilience in contexts outside of natural hazards and infectious disease outbreaks (i.e. armed conflict situations).

Each of the research team members ( 7 in total) was assigned a set of articles to review. Each article title was reviewed by the assigned researcher for relevancy using the previously mentioned inclusion and exclusion criteria, followed by a review of the abstract for those titles deemed relevant. All articles deemed relevant after title and abstract review were then read in their entirety by the assigned researcher, providing a final set of articles for analysis. Article references were also reviewed to identify important literature not located in the primary search. Articles were then thematically coded by the

\footnotetext{
${ }^{1}$ Kruk et al.'s definition of a resilient health system was used to inform the search terms because it was developed with broader expert input and because it addresses resilience within the context of infectious disease outbreaks and natural hazards.
}

assigned researcher using QRS International's NVivo 11 coding software [20] and a qualitative coding instrument developed from a priori themes previously identified in other resilience checklists [1,2,21,22]. Additional topics of interest that did not fit into the previously identified thematic rubric were coded as "other" for further review during data analysis. After completion of coding, through a process of inductive and deductive reasoning, the researchers identified a final list of themes and associated key literature that described the critical capacities necessary for health system resilience to infectious disease outbreaks and natural hazards. We then sought to identify areas of overlap between the health system resilience themes and capacities identified in our literature search, and the specific health security capacities that are the focus of the JEE.

\section{Results}

The search yielded a total of 1108 articles after the removal of duplicates (Additional file 3: Figure S1). One hundred and fifty-eight articles were read in their entirety, of which 132 were deemed to be relevant and underwent thematic coding. After the completion of coding, we identified 77 key documents that described 16 high-level themes of health system resilience, which are summarized in Additional file 1: Table S2 (see Additional file 2: Appendix A and Appendix B for a comprehensive breakdown of sources organized by theme and author). Thirty-nine papers focused primarily on infectious diseases, while another 12 addressed natural hazards. The remaining 26 papers were not threat-specific, but rather articulated general principles for strengthening health systems and described baseline capacities required for health system functioning. While the themes found in our search were consistent with the five elements of a resilient health system previously outlined by Kruk et al. [1, 2], we also identified three additional themes not included in previous reviews, including the need to:

- Develop policies for determining what level of care will be delivered when the level of demand exceeds existing resources;

- Plan for post-event recovery; and

- Commitment to quality improvement that ensures integration of lessons learned.

For example, Mehta et al. described the need to develop "altered standards of care" for responses to mass casualty events, which might include shifting resources to save as many lives as possible (i.e., triaging patients differently during emergencies as compared to normal operating conditions) and allowing for group isolation of patients that would normally be boarded in single rooms [23]. The literature identified a number of issues that must be addressed during the recovery phase of a public health emergency, including the need for grief and psychological 
counseling [24], after-action assessment and revision of emergency response plans [25], and rebuilding of social cohesion and trust [26]. A commitment to continuous quality improvement was also identified as an important component of resilient health systems, including making hospital performance ratings mandatory and publicly available to encourage peer competition with the primary goal being the overall improvement of hospital performance [27].

In integrating literature across subject areas, we were able to identify multiple references to the capacities necessary to achieve the 16 health system resilience attributes identified in our scoping review, which are summarized below (also see Additional file 1: Table S2).

- Core Health Service Capabilities: A resilient health system sustains baseline levels of routine healthcare delivery during a public health emergency [28-35].

- Barriers to Healthcare Access: A resilient health system dismantles barriers to healthcare access so that the public accesses care during emergencies [36, 37].

- Maintaining Critical Infrastructure and Transportation: A resilient health system develops plans to weather interruptions in critical infrastructure and transportation [24, 25, 38-50].

- Timely and Flexible Access to Emergency/Crisis Financing: A resilient health system has timely, flexible access to financing so that it can better prepare for and respond to public health emergencies [24, 29, 36, 37, 39-41, 51-59].

- Leadership and Command Structure: A resilient health system has a clear and flexible command structure that has been established prior to an event and is exercised frequently [24, 29, 57, 60-65].

- Collaboration, Coordination, and Partnerships: A resilient health system collaborates and coordinates with partners within and outside of the health system [2, 29, 39, 45, 57, 66, 67].

- Communication: A resilient health system has clear channels of communication between health system actors and other sectors, risk communication protocols, and robust engagement with patient populations $[60,68]$.

- Flexible Plans and Management Structures: A resilient health system has flexible plans and management structures to cope with rapidly evolving circumstances [1, 69-71].

- Legal Preparations: A resilient health system has made legal preparations to address challenges that may emerge during a crisis $[1,45,49,59,62,72,73]$.

- Surge Capacity: A resilient health system is able to call on human and capital resources to "surge" the level of care during public health emergencies [36, 74].
- Altered Standards of Care: A resilient health system has adaptable response plans to guide them in allocating scarce resources and healthcare services [23, 75].

- Health Workforce: A resilient health system has an adequate, trained, and willing work force $[4,22,36,40,45,53,54,76,77]$.

- Medical Supplies and Equipment: A resilient health system has access to medical supplies and equipment, including personal protective equipment, antivirals, and ventilators, during a crisis [40, 53, 78-80].

- Infection Prevention and Control (IPC): A resilient health system has implemented strong IPC measures, including staff training, standardized protocols, a dedicated IPC focal point, and dedicated treatment units [4, 22, 39, 47, 51, 54, 81-86].

- Commitment to Quality Improvement: A resilient health system requires a commitment to continuous quality improvement that promotes excellence and garners the trust of the community $[15,27,39,54,69,87,88]$.

- Plans for Post-Event Recovery: Resilient health systems have plans for post-event recovery that address a broad range of issues [24-26, 34, 40, 59, 73, 89-93].

The capacities that we identified are associated with different actors in health systems. Some of the capacities identified in our review could potentially be developed by individual health facilities. For example, Kim et al. discussed one health system's plan to develop alternate care centers that could be deployed during an influenza pandemic, including the infrastructure that needs to be in place to ensure adequate functioning, such as transport of patients to the center [42]. Other capacities identified in the scoping review concerned the health system more broadly and would likely be addressed by national governmental authorities. For example, Hanefeld et al. noted "the nature of the funding and financing mechanism as a core aspect enabling or hindering health systems' ability to respond to a shock" [29].

No frameworks were identified in the search that translated these high-level themes into specific and actionable steps that health system actors can employ to improve and support health system resilience to both infectious diseases and natural hazards, and that can be undertaken in low-, middle-, and high-income settings alike. Frameworks that did articulate specific capacities were either 1) only applicable in the US context [22] or 2) did not cohesively address both infectious diseases and natural disasters [50]. For example, Meyer et al. created a checklist for health sector resilience to highconsequence infectious diseases [22], but the data for 
this checklist was informed by the US domestic response to the 2014-2016 West Africa Ebola outbreak. While some of the identified capacities may be generalizable to other countries, some are only pertinent in the US context. Similarly, the Hospital Safety Index, a tool developed by WHO, does identify capacities that are relevant to some health facilities, but the tool is largely aimed at evaluating the vulnerability of hospital infrastructure to natural hazards (an updated version includes limited consideration of the potential impact of infectious disease threats to hospitals) [50].

Only two of the health system resilience themes and capacities identified in our literature search directly overlapped with the specific health security capacities that are the focus of the JEE-namely IPC and communication (See Additional file 1: Table S3). Specifically, the JEE indicator on antimicrobial resistance does address IPC, but only within the context of healthcareassociated infections and associated IPC programs [12]. Additionally, the literature we collected emphasized the importance of communication between health system actors, other sectors, and the community during outbreaks $[60,68]$. The JEE contains a very detailed section on communication that specifically calls out for the need for communication and coordination between stakeholders, including healthcare workers; for systems for rumor management through healthcare workers; and for formal communication mechanisms with the hospital and healthcare sector [12].

Otherwise, health facilities are not directly addressed in the JEE framework. There are some indicators in the JEE that do address the themes identified in the literature review, but only within the context of public health. For example, the literature suggests that health facilities need access to financing during emergencies to cover the added costs of preparing for and responding to emergencies [24, 29, 36, 37, 39-41, 51-59]. The JEE indicator on National, Legislation, Policy and Financing does address whether countries have the financing to fulfill their obligations under the IHR, which includes "regulations or administrative requirements, or other governmental instruments governing public health surveillance and response" [12]. However, it does not specifically address financing within the context of health facilities, although countries could choose to include them in efforts to develop capacities in those areas.

Finally, some of the themes identified in our review could be leveraged through the development of other capacities that are the focus of the JEE. For example, the JEE does not explicitly assess how healthcare facilities should address barriers to healthcare access, such as long travel distances, the high cost of medical care, and public distrust. However, it does address the importance of risk communication and community engagement during an emergency. These relationships could potentially be leveraged by the healthcare system during an emergency to improve the public's trust in and subsequent use of the healthcare system.

\section{Discussion}

To date, much of the literature that specifically references health system resilience has focused on high-level attributes, rather than identifying specific capacities that health systems need to be resilient to infectious disease outbreaks and natural hazards. For example, Kruk et al.'s five attributes of a resilient health system include a system that is "self-regulating," with the ability to "quickly identify and isolate a threat and target resources to it" [1]. By integrating literature from across different disciplines, we were able translate these high-level themes into actionable corresponding capacities that health systems need to respond to infectious disease outbreaks and natural hazards. For example, the literature highlighted numerous IPC protocols and practices that are important for the control of infectious disease threats, including the need for front-line healthcare workers to conduct travel histories [22] and the need to establish dedicated and multidisciplinary IPC committees to coordinate and guide healthcare staff on how to safely manage patients with infectious diseases [54, 84]. An article by Palagyi et al., published after this review was conducted, also highlights the importance of these capacities that we identified [94].

Additionally, the literature highlighted three themes not previously identified as attributes of a resilient health system, which warrant consideration in future efforts to define health system resilience. We present the capacities that we identified across the literature as merely the beginning of an effort to define capacities that health system actors need to be prepared for infectious disease outbreaks and natural hazards. Further scholarship in these areas could support efforts to translate research findings into best practices in public health and healthcare practice and improve health outcomes following public health emergencies of all kinds.

Notably, the JEE does identify the capacities necessary to implement the IHRs to protect against public health emergencies of international concern, but lacks guidance for health facilities at the patient-provider interface [12]. Moreover, many of the capacities assessed in the JEE presume the existence and functioning of core health system capacities, yet these capacities themselves are not explicitly addressed in JEE assessments. For example, while the presence of a national laboratory system-a JEE indicator-is a critical capacity to have during an outbreak, it requires that healthcare providers and the proper supplies be available to collect patient samples (e.g., blood, sputum, etc.). Ideally, efforts to improve health system resilience would complement and build 
upon those foundational capacities presumed by the JEE process.

The results of this literature review point to a need for increased integration of efforts to advance health security and health systems strengthening across the globe. Several high-priority elements for health systems resilience likely exist at the nexus of health systems strengthening, health system resilience, and health security; further work is needed to determine the most effective co-investments in global health security and health system strengthening that enable more robust health system responses at the local, national, regional, and global levels during emergent crises [95]. Identifying those areas of overlap can help to actualize the JEE's priority areas in health security, and also strengthen key components of national health systems such that their overall resilience is enhanced.

While we strived to capture all relevant health systems literature, a potential limitation to our review is the lack of consistency and definitional clarity with which terms like "health system" and "resilience" are used throughout the medical and public health literature. It is possible that we may have missed relevant articles that describe these concepts using different terms. We also found in the literature an overrepresentation of papers detailing health system impacts of certain events and, thus, our findings may not include considerations from other events not represented in the literature. Despite these limitations, we think our review serves to deepen the understanding of the specific capacities that health systems need to prepare for infectious diseases and natural hazards.

\section{Conclusions}

The themes and capacities identified in our literature review provide an initial step in refining the concept of health system resilience to enable actors across the various sectors of the health system to take action to be able to respond and recover from infectious disease outbreaks and natural hazards. There remains a need to further define the concept of resilience so that health systems can simultaneously achieve sustainable transformations in public health practice and health service delivery as well as improve their preparedness for emergencies. In the same way that the JEE tool has helped motivate countries to assess and improve their core public health capacities, an implementationoriented health system resilience framework could help translate the important components of a health system identified in this review into specific capacities that actors in the health system could work to develop to improve resilience to public health crises. Moreover, such an effort may help to integrate foundational health system capacities into national efforts to improve core public health capacities.

\section{Supplementary information}

Supplementary information accompanies this paper at https://doi.org/10. 1186/s12889-019-7707-z.

Additional file 1: Table S1. Electronic search strategy. Table S2. Summary of key themes and associated key evidence. Table S3. Overlap of scoping review themes with Joint External Evaluation indicators.

Additional file 2: Appendix A: Coding framework--the full coding framework is provided, along with definitions of each code, and the number and first author/publication year of all sources that were coded into each theme. Appendix B: Citations are provided for all sources referenced in appendix $A$.

Additional file 3: Figure S1. Selection of Sources of Evidence.

\section{Abbreviations}

IPC: Infection Prevention and Control; JEE: Joint External Evaluation; MERS: Middle East Respiratory Syndrome; SARS: Severe Acute Respiratory Syndrome; US: United States; WHO: World Health Organization

\section{Acknowledgements}

Not applicable.

\section{Authors' contributions}

JBN and DB conceived of and led the study. DM led the scoping review process. JBN, DM, MS, SJR, AL, JS, and DB participated in data collection, coding, and analysis. JBN and DM drafted the initial manuscript, and JBN, DM, MS, SJR, AL, JS, CIA and DB participated in its revision and review. All authors read and approved the final manuscript.

\section{Authors' information}

Johns Hopkins Center for Health Security (JBN, DM, SR, MS, CIA), Johns Hopkins Bloomberg School of Public Health (JS, AL, DB).

\section{Funding}

This research was supported by the Rockefeller Foundation. The Rockefeller Foundation had no role in the study design, data collection, data analysis and interpretation, in the writing of the report, or the decision to submit it for publication.

Availability of data and materials

not applicable.

Ethics approval and consent to participate

not applicable.

Consent for publication

not applicable.

\section{Competing interests}

The authors declare that they have no competing interests.

\section{Author details}

${ }^{1}$ Johns Hopkins Center for Health Security, 621 East Pratt Street, Suite 210, Baltimore, MD 21202, USA. 'Johns Hopkins Bloomberg School of Public Health, 615 N. Wolfe Street, Baltimore, MD 21205, USA.

Received: 10 May 2019 Accepted: 30 September 2019

Published online: 17 October 2019

References

1. Kruk ME, Myers M, Varpilah ST, Dahn BT. What is a resilient health system? Lessons from Ebola. Lancet. 2015;385(9980):1910-2.

2. Kruk ME, Ling EJ, Bitton A, Cammett M, Cavanaugh K, Chopra M, et al. Building resilient health systems: a proposal for a resilience index. BMJ. 2017;23:357-j2323

3. $\mathrm{WHO}$ | Ebola health worker infections [Internet]. WHO. Available from: http:// www.who.int/features/ebola/health-care-worker/en/. [cited 2018 Apr 24].

4. Gostin LO, Friedman EA. A retrospective and prospective analysis of the west African Ebola virus disease epidemic: robust national health systems at 
the foundation and an empowered WHO at the apex. Lancet. 2015; 385(9980):1902-9.

5. Chowell G, Abdirizak F, Lee S, Lee J, Jung E, Nishiura H, et al. Transmission characteristics of MERS and SARS in the healthcare setting: a comparative study. BMC Med. 2015;3:13 Available from: https://www.ncbi.nlm.nih.gov/ pmc/articles/PMC4558759/.

6. Webb GF, Blaser MJ, Zhu H, Ardal S, Wu J. Critical role of nosocomial transmission in the Toronto sars outbreak. Math Biosci Eng MBE. 2004;1(1):1-13.

7. Ki M. 2015 MERS outbreak in Korea: hospital-to-hospital transmission. Epidemiol Health. 2015;21:37 Available from: https://www.ncbi.nlm.nih.gov/ pmc/articles/PMC4533026/.

8. Redlener I, Reilly MJ. Lessons from Sandy — preparing health systems for future disasters. N Engl J Med. 2012;367(24):2269-71.

9. $\mathrm{WHO} \mid$ Report of the Ebola Interim Assessment Panel - July 2015 [Internet] WHO. Available from: http://www.who.int/csr/resources/publications/ebola/ ebola-panel-report/en/. [cited 2018 Apr 24].

10. Moon S, Sridhar D, Pate MA, Jha AK, Clinton C, Delaunay S, et al. Will Ebola change the game? Ten essential reforms before the next pandemic. The report of the Harvard-LSHTM independent panel on the global response to Ebola. Lancet. 2015;386(10009):2204-21.

11. Harvard Global Health Institute. Monitoring of Disease Outbreak Preparedness: A Shared Framework [Internet]. 2018. Available from: https://globalhealth.harvard.edu/monitoring-disease-preparedness. [cited 2019 Oct 14]

12. Assessments | Global Health Security Agenda [Internet]. Available from: https://www.ghsagenda.org/assessments. [cited 2018 Apr 25].

13. Strategic Partnership for IHR and Health Security (SPH) | Building Stronger Health Systems for Sustainable Health Security [Internet]. Available from: https://extranet.who.int/sph/jee-dashboard. [cited 2019 Feb 15].

14. ReadyScore Map [Internet]. Prevent Epidemics. Available from: https:// preventepidemics.org/ready-score-map/. [cited 2019 Mar 8].

15. Blanchet K, Nam SL, Ramalingam B, Pozo-Martin F. Governance and capacity to manage resilience of health systems: towards a new conceptual framework. Int J Health Policy Manag. 2017;6(8):431-5.

16. World Health Organization. Everybody's business -- strengthening health systems to improve health outcomes: WHO's framework for action [Internet]. 2007. Available from: https:/apps.who.int/iris/handle/10665/43918.

17. World Health Organization. Monitoring the building blocks of health systems: a handbook of indicators and their measurement strategies [Internet]. 2010. Available from: https://www.who.int/healthinfo/systems/monitoring/en/.

18. Turenne CP, Gautier L, Degroote S, Guillard E, Chabrol F, Ridde V. Conceptual analysis of health systems resilience: a scoping review. Soc Sci Med. 2019;232:168-80.

19. The World Health Report 2000, Health Systems: Improving Performance [Internet]. World Health Organization; 2000. Available from: https://www. who.int/whr/2000/en/whr00_en.pdf?ua=1. [cited 2019 Jan 11].

20. NVivo Qualitative Data Analysis Software. QRS International Pty Ltd. 2015. Available from: https://www.qsrinternational.com/nvivo/home. [cited 2019 Oct 14].

21. Toner ES, McGinty M, Schoch-Spana M, Rose DA, Watson M, Echols E, et al. A community checklist for health sector resilience informed by hurricane Sandy. Health Secur. 2017;15(1):53-69.

22. Meyer D, Kirk Sell T, Schoch-Spana M, Shearer MP, Chandler H, Thomas E, et al. Lessons from the domestic Ebola response: improving health care system resilience to high consequence infectious diseases. Am J Infect Control. 2018;46(5):533-7.

23. Mehta S. Disaster and mass casualty management in a hospital: how well are we prepared? J Postgrad Med. 2006;52(2):89.

24. Elston JWT, Cartwright C, Ndumbi P, Wright J. The health impact of the 2014-15 Ebola outbreak. Public Health. 2017;143:60-70.

25. Moore BL, Geller RJ, Clark C. Hospital preparedness for chemical and radiological disasters. Emerg Med Clin North Am. 2015;33(1):37-49.

26. Shultz JM, Cooper JL, Baingana F, Oquendo MA, Espinel Z, Althouse BM, et al. The role of fear-related behaviors in the 2013-2016 West Africa Ebola virus disease outbreak. Curr Psychiatry Rep. 2016;18(11):104.

27. Shibuya K, Hashimoto H, Ikegami N, Nishi A, Tanimoto T, Miyata H, et al. Future of Japan's system of good health at low cost with equity: beyond universal coverage. Lancet Lond Engl. 2011;378(9798):1265-73.

28. Elliott A, Rehfisch N. Mortuary provision in emergencies causing mass fatalities. J Bus Contin Emer Plan. 2011;5(1):430-9.
29. Hanefeld J, Mayhew S, Legido-Quigley H, Martineau F, Karanikolos M, Blanchet $\mathrm{K}$, et al. Towards an understanding of resilience: responding to health systems shocks. Health Policy Plan. 2018;33(3):355-67.

30. Lapão LV, Silva A, Pereira N, Vasconcelos P, Conceição C. Ebola impact on African health systems entails a quest for more international and local resilience: the case of African Portuguese speaking countries. Pan Afr Med J. 2015;22(Suppl):1-15.

31. Lohman N, Hagopian A, Luboga SA, Stover B, Lim T, Makumbi F, et al. District health officer perceptions of PEPFAR's influence on the health system in Uganda, 2005-2011. Int J Health Policy Manag. 2016;6(2):83-95.

32. Loubet $P$, Mabileau $G$, Baysah M, Nuta C, Taylor M, Jusu $H$, et al. Likely effect of the 2014 Ebola epidemic on HIV care in Liberia. AIDS Lond Engl. 2015 Nov;29(17):2347-51.

33. Orenstein WA, Seib K. Beyond vertical and horizontal programs: a diagonal approach to building national immunization programs through measles elimination. Expert Rev Vaccines. 2016;15(7):791-3.

34. Reinhardt JD, Li J, Gosney J, Rathore FA, Haig AJ, Marx M, et al. Disability and health-related rehabilitation in international disaster relief. Glob Health Action. 2011:4:7191.

35. Siekmans K, Sohani S, Boima T, Koffa F, Basil L, Laaziz S. Community-based health care is an essential component of a resilient health system: evidence from Ebola outbreak in Liberia. BMC Public Health. 2017;17 Available from: https://www.ncbi.n/m.nih.gov/pmc/articles/PMC5240441/. Accessed 24 Apr 2018

36. Ammar W, Kdouh O, Hammoud R, Hamadeh R, Harb H, Ammar Z, et al. Health system resilience: Lebanon and the Syrian refugee crisis. J Glob Health. 2016;6(2) Available from: https://www.ncbi.nlm.nih.gov/pmc/articles/ PMC5234495/. Accessed 24 Apr 2018.

37. Liu Y. China's public health-care system: facing the challenges. Bull World Health Organ. 2004;82(7):532-8.

38. Ardagh MW, Richardson SK, Robinson V, Than M, Gee P, Henderson S, et al. The initial health-system response to the earthquake in Christchurch, New Zealand, in February, 2011. Lancet. 2012;379(9831):2109-15.

39. Cancedda C, Davis SM, Dierberg KL, Lascher J, Kelly JD, Barrie MB, et al. Strengthening health systems while responding to a health crisis: lessons learned by a nongovernmental organization during the Ebola virus disease epidemic in Sierra Leone. J Infect Dis. 2016;214(suppl 3):S153-63.

40. Jones S, Sam B, Bull F, Pieh SB, Lambert J, Mgawadere F, et al. "Even when you are afraid, you stay": provision of maternity care during the Ebola virus epidemic: a qualitative study. Midwifery. 2017;52:19-26.

41. Kearns RD, Holmes JH, Skarote MB, Cairns CB, Strickland SC, Smith HG, et al. Disasters; the 2010 Haitian earthquake and the evacuation of burn victims to US burn centers. Burns J Int Soc Burn Inj. 2014;40(6):1121-32.

42. Kim CS, Pile JC, Lozon MM, Wilkerson WM, Wright CM, Cinti S. Role of hospitalists in an offsite alternate care center (ACC) for pandemic flu. J Hosp Med. 2009;4(9):546-9.

43. Kingham TP, Kamara TB, Cherian MN, Gosselin RA, Simkins M, Meissner C, et al. Quantifying surgical capacity in Sierra Leone: a guide for improving surgical care. Arch Surg. 2009;144(2):122-7.

44. Pouraghaei M, Jannati A, Moharamzadeh P, Ghaffarzad A, Heshmati Far M, Babaie J. Challenges of hospital response to the twin earthquakes of august 21, 2012, in East Azerbaijan. Iran Disaster Med Public Health Prep. 2017;11:1-9.

45. Rozeman PA, Mayeaux EJ. Hurricanes Katrina and Rita: evacuee healthcare efforts remote from hurricane affected areas. South Med J. 2006;99(12):1329-33.

46. Saghafi NM. Survey of the bam earthquake survivors' opinions on medical and health system services. Prehosp Disaster Med. 2008;23(4):382.

47. Shoman H, Karafillakis E, Rawaf S. The link between the West African Ebola outbreak and health systems in Guinea, Liberia and Sierra Leone: a systematic review. Glob Health. 2017;13 Available from: https://www.ncbi. nlm.nih.gov/pmc/articles/PMC5210305/. Accessed 24 Apr 2018.

48. Tran TM, Saint-Fort M, Jose M-D, Henrys JH, Pierre Pierre JB, Cherian MN, et al. Estimation of surgery capacity in Haiti: nationwide survey of hospitals. World J Surg. 2015;39(9):2182-90.

49. Yakubu A, Folayan MO, Sani-Gwarzo N, Nguku P, Peterson K, Brown B. The Ebola outbreak in Western Africa: ethical obligations for care. J Med Ethics. 2014. https://doi.org/10.1136/medethics-2014-102434.

50. Ariscain VH, https://www.facebook.com/pahowho. PAHO/WHO Health Emergencies - The Hospital Safety Index | PAHO/WHO [Internet]. Pan American Health Organization / World Health Organization. Available from: https://www.paho.org/disasters/index.php?option=com_content\&view= article\&id=964:safety-index\&ltemid=912\&lang=en. [cited 2019 Jan 11]. 
51. DeBiasi RL, Song X, Cato K, Floyd T, Talley L, Gorman K, et al. Preparedness, evaluation, and care of pediatric patients under investigation for Ebola virus disease: experience from a pediatric designated care facility. J Pediatr Infect Dis Soc. 2016;5(1):68-75.

52. Elmahdawy M, Elsisi GH, Carapinha J, Lamorde M, Habib A, Agyie-Baffour P, et al. Ebola virus epidemic in West Africa: global health economic challenges, lessons learned, and policy recommendations. Value Health Reg Issues. 2017;13:67-70.

53. Felland LE, Katz A, Liebhaber A, Cohen GR. Developing health system surge capacity: community efforts in jeopardy. Res Brief. 2008;5:1-8.

54. Harries AD, Zachariah R, Tayler-Smith K, Schouten EJ, Chimbwandira F, Van Damme W, et al. Keeping health facilities safe: one way of strengthening the interaction between disease-specific programmes and health systems. Tropical Med Int Health. 2010;15(12):1407-12.

55. Ivers LC. Strengthening the health system while investing in Haiti. Am J Public Health. 2011;101(6):970-1.

56. Karanikolos M, Heino P, McKee M, Stuckler D, Legido-Quigley H. Effects of the global financial crisis on health in high-income Oecd countries: a narrative review. Int J Health Serv Plan Adm Eval. 2016;46(2):208-40.

57. Van Minh H, Tuan Anh T, Rocklöv J, Bao Giang K, Trang LQ, Sahlen K-G, et al. Primary healthcare system capacities for responding to storm and flood-related health problems: a case study from a rural district in central Vietnam. Glob Health Action. 2014;7 Available from: https://www.ncbi.nlm. nih.gov/pmc/articles/PMC4265642/. Accessed 24 Apr 2018.

58. Wurie HR, Samai M, Witter S. Retention of health workers in rural Sierra Leone: findings from life histories. Hum Resour Health. 2016;14:3.

59. Zhong S, Clark M, Hou X-Y, Zang Y, FitzGerald G. Progress and challenges of disaster health management in China: a scoping review. Glob Health Action. 2014;7:24986.

60. Cleary V, Balasegaram S, McCloskey B, Keeling D, Turbitt D. Pandemic (H1N1) 2009: setting up a multi-agency regional response centre--a toolkit for other public health emergencies. J Bus Contin Emer Plan. 2010;4(2):154-64.

61. Dhanoa T, Fuller H, Herechuk B, Trowbridge S, Raab V, MacDonald AM, et al. Response to a serious flood: the St Joseph's healthcare experience. Healthc Q Tor Ont. 2014;17(4):58-62.

62. McMahon SA, Ho LS, Scott K, Brown H, Miller L, Ratnayake R, et al. "We and the nurses are now working with one voice": How community leaders and health committee members describe their role in Sierra Leone's Ebola response. BMC Health Serv Res. 2017;17(1):495.

63. Regmi K, Gilbert R, Thunhurst C. How can health systems be strengthened to control and prevent an Ebola outbreak? A narrative review. Infect Ecol Epidemiol. 2015;5:28877.

64. Varma JK, Prezant DJ, Wilson R, Quinn C, Asaeda G, Cagliuso NV, et al. Preparing the health system to respond to Ebola virus disease in New York City, 2014. Disaster Med Public Health Prep. 2017;11(3):370-4.

65. Yantao X. Assessment of hospital emergency management in the Beijing area. Prehosp Disaster Med. 2011;26(3):180-3.

66. Chi GC, Williams M, Chandra A, Plough A, Eisenman D. Partnerships for community resilience: perspectives from the Los Angeles County community disaster resilience project. Public Health. 2015;129(9):1297-300

67. Lurie N, Valdez RB, Wasserman J, Stoto MA, Myers S, Molander RC, et al. Public Health preparedness in California: lessons learned from seven health jurisdictions [Internet]: RAND Corporation; 2004. Available from: https:// www.rand.org/pubs/technical_reports/TR181.html. [cited 2019 Apr 15]

68. Beard L, Clark C. SARS: a health system's perspective. Hosp Q. 2003;6(4(4):55-8.

69. Barasa EW, Cloete K, Gilson L. From bouncing back, to nurturing emergence: reframing the concept of resilience in health systems strengthening. Health Policy Plan. 2017;32(suppl_3):iii91-4.

70. Gizelis T-I, Karim S, Østby G, Urdal H. Maternal health care in the time of Ebola: a mixed-method exploration of the impact of the epidemic on delivery services in Monrovia. World Dev. 2017;98:169-78.

71. Martineau FP. People-centred health systems: building more resilient health systems in the wake of the Ebola crisis. Int Health. 2016;8(5):307-9.

72. Campbell A. The SARS commission interim report: SARS and public health in Ontario. Biosecurity Bioterrorism Biodefense Strategy Pract Sci. 2004;2(2):118-26.

73. Verni C. A hospital system's response to a hurricane offers lessons, including the need for mandatory interfacility drills. Health Aff Proj Hope. 2012;31(8):1814-21.

74. Therrien M-C, Normandin J-M, Denis J-L. Bridging complexity theory and resilience to develop surge capacity in health systems. J Health Organ Manag. 2017;31(1):96-109.
75. Institute of Medicine (US). Barriers to integrating crisis standards of care principles into international disaster response plans: workshop summary [Internet]. Washington (DC): National Academies Press (US); 2012. (The National Academies Collection: Reports funded by National Institutes of Health). Available from: http://www.ncbi.nlm.nih.gov/ books/NBK91501/

76. Lewis JD, Enfield KB, Perl TM, Sifri CD. Preparedness planning and care of patients under investigation for or with Ebola virus disease: a survey of physicians in North America. Am J Infect Control. 2017; 45(1):65-8.

77. Raven J, Baral S, Wurie H, Witter S, Samai M, Paudel P, et al. What adaptation to research is needed following crises: a comparative, qualitative study of the health workforce in Sierra Leone and Nepal. Health Res Policy Syst. 2018;16(1):6.

78. Rebmann T, McPhee K, Osborne L, Gillen DP, Haas GA. Best practices for healthcare facility and regional stockpile maintenance and sustainment: a literature review. Health Secur. 2017;15(4):409-17.

79. Reece S, Brown CS, Dunning J, Chand MA, Zambon MC, Jacobs M. The UK's multidisciplinary response to an Ebola epidemic. Clin Med (Lond). 2017; 17(4):332-7.

80. Schwanke Khilji SU, Rudge JW, Drake T, Chavez I, Borin K, Touch S, et al. Distribution of selected healthcare resources for influenza pandemic response in Cambodia. Int J Equity Health. 2013;12:82.

81. Barden-O FJ, Barry MA, Brodish P, Hazerjian J. Rapid assessment of Ebola-related implications for reproductive, maternal, newborn and child health service delivery and utilization in Guinea. PLOS Curr Outbreaks. 2015; Available from: http://currents.plos.org/outbreaks/article/rapidassessment-of-ebola-related-implications-for-reproductive-maternalnewborn-and-child-health-service-delivery-and-utilization-in-guinea/. [cited 2018 Apr 24].

82. Cooper C, Fisher D, Gupta N, MaCauley R, Pessoa-Silva CL. Infection prevention and control of the Ebola outbreak in Liberia, 2014-2015: key challenges and successes. BMC Med. 2016;14 Available from: https://www.ncbi.nlm.nih.gov/pmc/articles/PMC4702360/. Accessed 24 Apr 2018.

83. Elston JWT, Moosa AJ, Moses F, Walker G, Dotta N, Waldman RJ, et al. Impact of the Ebola outbreak on health systems and population health in Sierra Leone. J Public Health. 2016;38(4):673-8.

84. Pathmanathan I, O'Connor KA, Adams ML, Rao CY, Kilmarx PH, Park BJ, et al. Rapid assessment of Ebola infection prevention and control needs--six districts, Sierra Leone, October 2014. MMWR Morb Mortal Wkly Rep. 2014;63(49):1172-4.

85. Singh SR, Coker R, Vrijhoef HJ-M, Leo YS, Chow A, Lim PL, et al. Mapping infectious disease hospital surge threats to lessons learnt in Singapore: a systems analysis and development of a framework to inform how to DECIDE on planning and response strategies. BMC Health Serv Res. 2017; 17(1):622.

86. Subhash SS, Baracco G, Miller SL, Eagan A, Radonovich LJ. Estimation of needed isolation capacity for an airborne influenza pandemic. Health Secur. 2016;14(4):258-63.

87. Strengthening resilience: a priority shared by Health 2020 and the sustainable development goals [Internet]. World Health Organization; 2017. Available from: http://www.euro.who.int/_data/assets/pdf file/0005/3512 84/resilience-report-20171004-h1635.pdf. Accessed 15 Apr 2018.

88. Hafner T, Walkowiak H, Lee D, Aboagye-Nyame F. Defining pharmaceutical systems strengthening: concepts to enable measurement. Health Policy Plan. 2017;32(4):572-84.

89. Recovery toolkit: Supporting countries to achieve health service resilience [Internet]. World Health Organization; 2016. Available from: https://www.who.int/ csr/resources/publications/ebola/recovery-toolkit/en/. Accessed 15 Apr 2018.

90. Fitter DL, Delson DB, Guillaume FD, Schaad AW, Moffett DB, Poncelet J$L$, et al. Applying a new framework for public health systems recovery following emergencies and disasters: the example of Haiti following a major earthquake and cholera outbreak. Am J Trop Med Hyg. 2017; 97(4_Suppl):4-11.

91. McPake B, Witter S, Ssali S, Wurie H, Namakula J, Ssengooba F. Ebola in the context of conflict affected states and health systems: case studies of Northern Uganda and Sierra Leone. Confl Heal. 2015:9:23.

92. Oliveira C, Russo G. Vertical interventions and system effects; have we learned anything from past experiences? Pan Afr Med J. 2015;21:262.

93. Tambo E, Chengho CF, Ugwu CE, Wurie I, Jonhson JK, Ngogang JY. Rebuilding transformation strategies in post-Ebola epidemics in Africa. Infect Dis Poverty. 2017;6(1):71. 
94. Palagyi A, Marais BJ, Abimbola S, Topp SM, McBryde ES, Negin J. Health system preparedness for emerging infectious diseases: a synthesis of the literature. Glob Public Health. 2019;14:1-22.

95. WHO | Health security and health systems strengthening - an integrated approach [Internet]. WHO. Available from: http://www.who.int/csr/disease/ ebola/health-systems-recovery/health-security/en/. [cited 2019 Jan 11].

\section{Publisher's Note}

Springer Nature remains neutral with regard to jurisdictional claims in published maps and institutional affiliations.

Ready to submit your research? Choose BMC and benefit from:

- fast, convenient online submission

- thorough peer review by experienced researchers in your field

- rapid publication on acceptance

- support for research data, including large and complex data types

- gold Open Access which fosters wider collaboration and increased citations

- maximum visibility for your research: over $100 \mathrm{M}$ website views per year

At $\mathrm{BMC}$, research is always in progress.

Learn more biomedcentral.com/submissions 